Special Issue of the 6th International Congress \& Exhibition (APMAS2016), Maslak, Istanbul, Turkey, June 1-3, 2016

\title{
Investigation of the Delamination Factor of Glass Sphere and Silicon Particle Reinforced (GS-SCR) Hybrid Composite Material
}

\author{
M. DUNDAR ${ }^{a, *}$, F. FiCICI ${ }^{b}$, F. OZEN ${ }^{b}$ AND H. UNAL ${ }^{b}$ \\ ${ }^{a}$ Canakkale Onsekiz Mart University, Biga Vocational School, 17200 Canakkale, Turkey \\ ${ }^{b}$ Sakarya University, Faculty of Technology, 54187, Sakarya, Turkey
}

\begin{abstract}
Reinforced polymer composite materials have opened a new era because they can substitute the conventional metallic materials. These materials have found numerous usage areas, especially in aviation, military and space applications due to such advantages as the high tensile strength, high modulus, high corrosion resistance and low density. However, during the assembly of parts from these materials, a huge amount of holes is required. There are problems during machining of reinforced polymer composite materials. Main reason behind these problems is the inhomogeneous microstructure. Some of these problems are burr, pullout, swelling, microcrack, rapid tool wear and delamination. Among the most important of these defects is the delamination damage. Delamination is a severe drilling failure. In this work, three different cutting speeds $(15,20,25 \mathrm{~m} / \mathrm{min})$, three different feed rates $(0.05,0.10,0.15 \mathrm{~mm} / \mathrm{rev})$ and three different cutting tool materials (Carbide, TiN Coated HSS and HSS) have been used. Effect of different feed rates, cutting speeds and tool materials on delamination is studied by drilling of $\% 10$ glass sphere- and $\% 10$ silicon particle-reinforced polypropylene hybrid composite material.
\end{abstract}

DOI: 10.12693/APhysPolA.131.595

PACS/topics: 72.80.Tm

\section{Introduction}

Reinforced polymer composite (RPC) materials consist of two phases. The first of them is reinforcement phase and the second is the matrix material, which works as binder of reinforcement phases. It is generally made from thermoplastic or thermoset resins [1].

For the last decades, RPC materials have found a wide range of applications, especially in aircraft, spacecraft and military uses, because they have superior properties, when compared to conventional materials. Some of them are high strength-to-weight ratio, high fracture toughness, high corrosion resistance, and ability to be manufactured in a great variety of shapes [2].

To attach parts of these specific materials to their location on a vehicle or craft, a huge amount of holes is needed. Drilling is the most utilized machining operation with RPC materials [3]. Although being the most employed operation, drilling of RPC materials is not easy. While drilling of RPC materials, some serious problems are confronted. Some of these problems are fiber breakage, burr, pullout, fiber-matrix stripping, fuzzing, swelling, microcrack, rapid tool wear and delamination [4]. The most important among these problems is delamination. It is reported that, during final assembly in aviation industry, part rejections which arise from delamination damage may be as high as $60 \%$ of all composite material rejections [5]. Delamination is a highly

*corresponding author; e-mail: m.dundar@comu.edu.tr important defect, because it lowers bearing capacity, adversely affects RPCs long term performance and gives rise to bad assembly tolerances by delaminating the hole [6].

Hybrid composites can be defined as consisting of two or more types of reinforcement phase in the same matrix. The main motivation for mixing the two or more reinforcement phases is to boost the properties of composite material [7]. These reinforcement phases are adjusted or added according to design conditions of composite material. In this work, $10 \%$ glass spheres- and $10 \%$ of silicon particle-reinforced polypropylene hybrid composite material has been used. Influence of different feed rates, different cutting speeds and different cutting tool materials on delamination has been investigated.

\section{Experimental procedure}

The workpiece material specimens having size of $25 \times$ $10 \times 5 \mathrm{~mm}^{3}$, were fabricated using compression molding technique. Experimental drilling tests were performed in HAAS TM1 CNC milling machine with $5.6 \mathrm{~kW}$ spindle power and $4000 \mathrm{rpm}$ maximum rotational speed, which can be seen in Fig. 1. Drill bits used throughout the tests were all $5 \mathrm{~mm}$ in diameter, of three different cutting materials: high speed steel (HSS), TiN coated HSS and carbide (K20), with point angles of $118^{\circ}$ and a helix angle of $30^{\circ}$. The experiments were conducted at three cutting speeds and different feed rates, given in Table I. The delamination was measured with a shop microscope, Nikon Eclipse L150, with 30× magnification and $1 \mu \mathrm{m}$ resolution. 


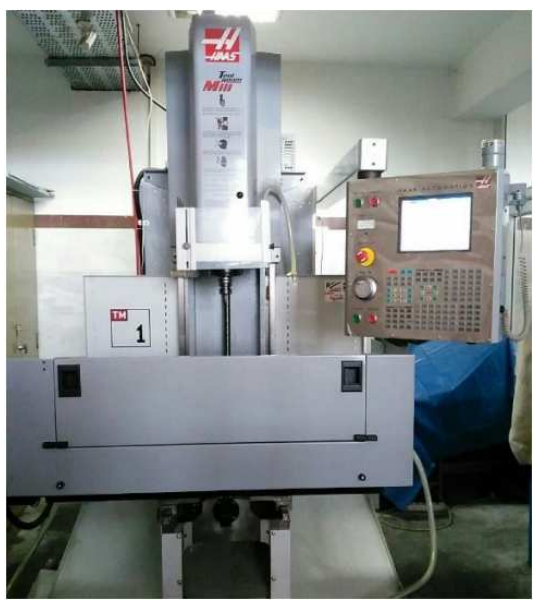

Fig. 1. CNC milling machine.

TABLE I

Machining parameters and levels.

\begin{tabular}{c|c|c|c}
\hline \hline & I & II & III \\
\hline Cutting speed & 15 & 20 & 25 \\
Feed rate & 0.05 & 0.1 & 0.15 \\
Cutting tool & HSS & TiN Coated HSS & Carbide (K20)
\end{tabular}

\section{Results and discussion}

Figures 2 and 3 show the influence of cutting speed and feed rate on delamination factor when drilling hybrid composite materials using the three different tool materials.

Figure 2 shows that the delamination factor increases with cutting velocity due to the fact that the temperature produced in drilling of composites softens the matrix material and results in shearing [8]. This finding has close relationship with the results presented by Rajamurugan and Palanikumar [9, 10].

Khashaba et al. have investigated the effects of the drilling parameters, speed, and feed rate, on the required cutting forces and torques in drilling chopped composites with different fiber volume fractions. They have observed that the delamination factor increases with increasing the feed rate, whereas no clear effect of the cutting speed on the delamination factor is observed.

The results from Fig. 3 indicate that the surface roughness increases linearly at higher feed rates, which cause the increases the thrust force and fracture of the composite materials. This is consistent with the results from the study of Latha and Senthilkumar [11]. They have reported that the feed rate is the main factor which influences the thrust force in drilling of GFRP composites.

Comparison of the effects of the three different tested drill materials shows that the HSS drill provides higher delamination factor values (see Figs. 2, and 3). The K10 carbide drill gave the best results. The second best results were obtained by coated $\mathrm{HSS}+\mathrm{TiN}$ drill.
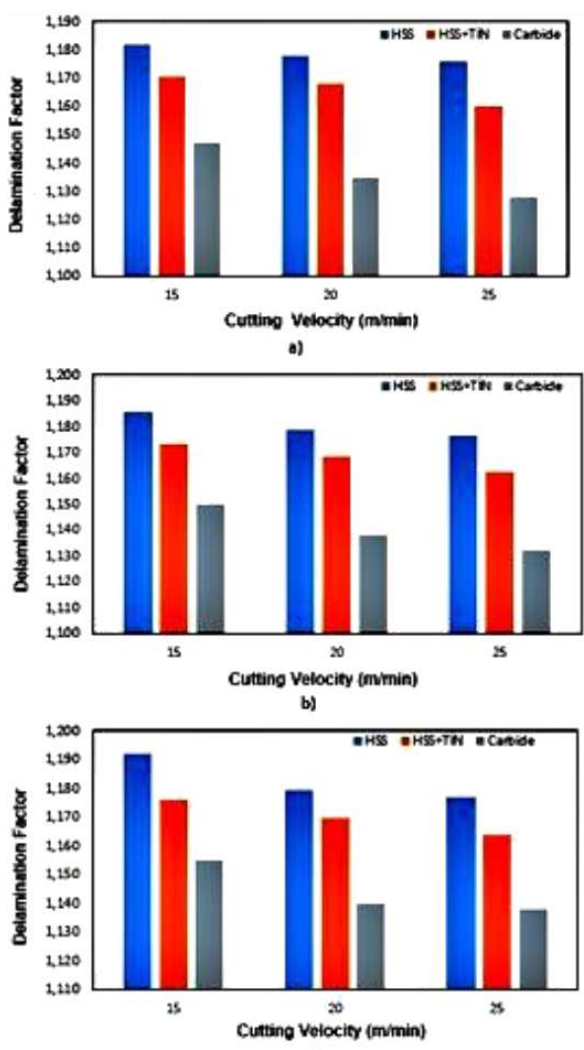

Fig. 2. The effect of cutting speed on the delamination factor.

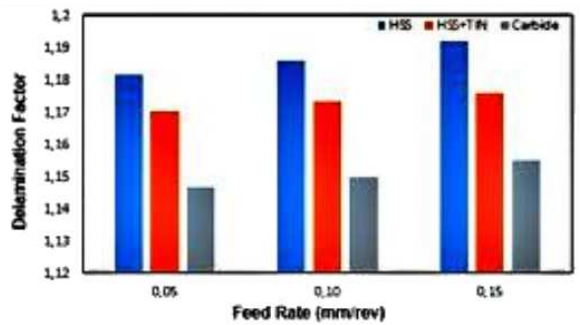

a)

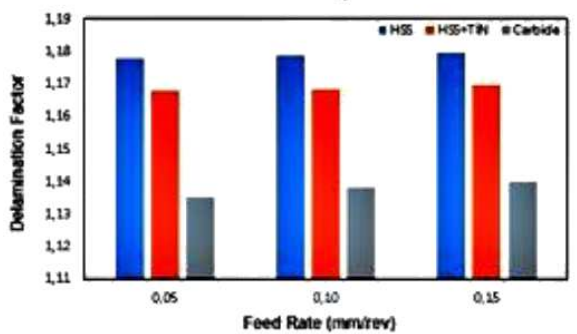

b)

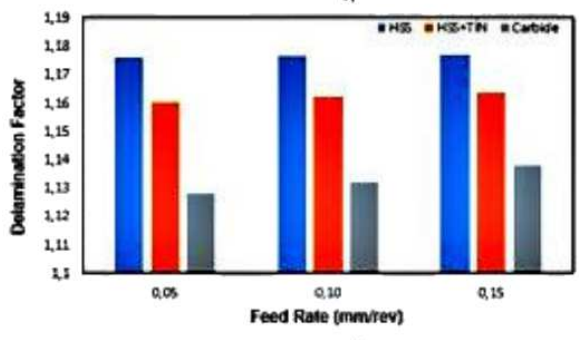

c)

Fig. 3. The effect of feed rate on the delamination factor. 
The experimental result presented is similar to the result presented by Davim and Reis [12]. Davim and Reis [12] have carried out study on drilling of carbon fibre reinforced plastic (CFRP) composites using statistical technique. They have observed that the K10 carbide drill promotes less damage on composite laminate than HSS drill.

\section{Conclusions}

In this study, drilling of GS-SPR hybrid composite materials was performed and delamination factor has been studied by using three different cutting tools. From the experimental test the following conclusions have been drawn:

1. The experimental results show that the delamination factor increases with the increase of feed rate.

2. The delamination factor decreases with the increase of cutting speed.

3. The feed rate, cutting speed and cutting tool type are seen to make the largest contribution to the delamination effect.

4. The best results were obtained with the carbide drill.

\section{Acknowledgments}

The authors would like to thank to Sakarya University Scientific Research Foundation (Project number : (201550-01-052) for their support.

\section{References}

[1] R. Melentiev, P.C. Priarone, M. Robiglio, L. Settineri, Procedia CIRP. 45, 31 (2016).

[2] H. Hocheng, C.C. Tsao, H.T. Chen, Comp. Struct. 139, 36 (2016).

[3] J. Ramkumar, S.K. Malhotra, R. Krishnamurthy, Mater. Manuf. Process 17, 213 (2002).

[4] S. Arul, L. Vijayaraghavan, S.K. Malhotra, R. Krishnamurthy, Int. J. Mach. T. Manuf. 46, 252 (2006).

[5] T. Sunny, J. Babu, J. Philip, Proced. Mater. Science 6, 1131 (2014).

[6] J.C. Rubio, A.M. Abrao, P.E. Faria, A.E. Correia, P. Davim Int. J. Mach. T. Manuf. 48, 715 (2008).

[7] M.J.M. Ridzuan, M.S.A. Majid, M. Afendi, M.N. Mazlee, A.G. Gibson, Comp. Struct. 152, 850 (2016).

[8] K. Palanikumar, Measurement 44, 2138 (2011).

[9] T.V. Rajamurugan, K. Shanmugan, K. Palanikumar, Mater. Des. 45, 80 (2013).

[10] K. Palanikumar, S. Prakash, K. Shanmugam Mater. Manuf. Process 23, 858 (2008).

[11] B. Latha, V.S. Sentilkumar, J. Reinforced Plas. Comp. 28, 951 (2008).

[12] J.P. Davim, P. Reis, Comp. Structures 59, 481 (2003). 